\title{
Diminishing Solar Radiation as a Driving Factor of Changes in Space Laboratory: A Study of March 29th 2006 Eclipse As Viewed and Monitored In Katsina State, Nigeria
}

\author{
Darma, M. R. ${ }^{1}$ and Kankara, I. A ${ }^{2}$
}

\begin{abstract}
On Wednesday, $29^{\text {th }} 2006$ suddenly a Solar Eclipse erupted in Katsina State $\left(12^{0} 15^{\prime} \mathrm{N}, 7^{0} 30^{\prime} \mathrm{E}\right)$ in Northern Nigeria at around 11: 16 am Nigerian GMT, which also lasted for about 40 minutes. It was, before then speculated that it was going to happen. But then, many local Climatic predictors alongside ignorant local residents presumed it was just a speculation and mere fantasy. In the Eclipse, there was an instant cut-off of solar radiant energy which also affected the many Biological clocks of many Ecosystems and even beyond. During the incidence, there were many changes in Environmental parameters. At the time of the total eclipse of the sun by moon both the air temperature and the Radiant energy attained a maximum stage. Equally, Aerosol Optical Depth (AOD) and Relative Humidity (RH) rose to maximum before clocking back to normal values. Scientific calculations and or measurements are needed during this period in order to find out any adverse conditions on any living specie in the affected area. With abrupt decrease in incoming sun's radiation and temperature and an increase in humidity, if prolonged could impose changes on precipitation, freezing points, flooding, and so on. Solar Eclipse in turn provides a natural space laboratory for measurement of diffused Radiation and its effect on Ecosystems, if there be. This paper observes some scientific changes as observed during the Eclipse that affected the optimum conditions of living species.
\end{abstract}

Keywords-Atmospheric Geochemistry, Eclipse, Natural Space Laboratory, Katsina State, Nigeria.

\section{INTRODUCTION}

$\mathrm{T}$ HE Moon's orbit around the Earth is an ellipse as is the Earth's orbit around the Sun. The apparent sizes of the Sun and Moon therefore vary. The magnitude of an eclipse is the ratio of the apparent size of the Moon to the apparent size of the Sun during an eclipse. An eclipse that occurs when the Moon is near its closest distance to Earth (i.e., near its perigee) can be a total eclipse because the Moon will appear to be large enough to completely cover the Sun's bright disk, or photosphere; a total eclipse has a magnitude greater than 1 . Conversely, an eclipse that occurs when the Moon is near its farthest distance from Earth (i.e., near its apogee) can only be an annular eclipse because the Moon will appear to be slightly

\footnotetext{
${ }^{1}$ Pleasant Engineering and Technical Services Katsina

${ }^{2}$ Department of Geography and Regional Planning, Federal University Dutsin-Ma.
}

smaller than the Sun; the magnitude of an annular eclipse is less than 1 . Slightly more solar eclipses are annular than total because, on average, the Moon lies too far from Earth to cover the Sun completely. A hybrid eclipse occurs when the magnitude of an eclipse changes during the event from less to greater than one, so the eclipse appears to be total at some locations on Earth and annular at other locations.

Because the Earth's orbit around the Sun is also elliptical, the Earth's distance from the Sun similarly varies throughout the year. This affects the apparent size of the Sun in the same way, but not as much as does the Moon's varying distance from Earth. When Earth approaches its farthest distance from the Sun in July, a total eclipse is somewhat more likely, whereas conditions favor an annular eclipse when Earth approaches its closest distance to the Sun in January. Unexpected Consequences of a Solar Eclipse [1]

Solar Eclipse, like that of March 29, 2006, is an event that occurs infrequently at any particular location. The Moon traverses an orbit in space around the Earth while the Earth traverses an elliptical orbit around the Sun. When the Moon's position comes in between the Earth and the Sun, the Sun's rays will be blocked resulting in an Eclipse of the Sun. The Eclipse can be total (resulting in total darkness) or partial. The Eclipse of March 29, 2006 reached its total at Katsina, Katsina State, Nigeria. The effect of the eclipse includes diminishing intensity of incident radiation coming from Sun at various wavelengths of the electron magnetic spectrum, change in temperature, relative humidity, and night and day biological and psychological effects in living things. This unique occurrence can be considered as a Space Laboratory where the effects of the event on measurable parameters can be estimated. The diminishing solar radiation is the primary driving factor of the other changes, which also alter the natural arrangement of space Laboratory. Observation of solar radiation and other environmental parameters were ongoing at Katsina city in collaboration with the Energy Research Center Ahmadu Bello University Zaria, Nigeria and as part of the Baseline Surface Radiation Network (BSRN) effort. Measurements of several parameters made during the Eclipse at Katsina are reported in this paper [2].

Under the International Helioscopic Year (IHY) NASA provided the expected temporal trajectory of the moon during the Eclipse through the West African Sub-region (Espenak and 
Anderson, 2006) as well as protective goggles to observe it. The eclipse could then be viewed sequentially as the moon covered the sun disc. It was observed that at local time, time of 10:30 (9:30 GMT), the moon completely blocked the sun, namely, the total eclipse occurred between 9:23 and 9:27 GMT. An armature collimator and photo-sensor that converts solar radiation to electrical energy was aimed at the Sun for direct viewing of the eclipse, and the radiation during the eclipse was recorded in an arbitrary unit. The minimum solar radiation flux occurred during the maximum coverage of the Sun disc (figure 2). This time is found to agree with the interpolated value from Espenak and Anderson (2006). Having correctly identified the time of occurrence of the total Eclipse, it was possible to analyze the data collected at the Ilorin site. The experimental procedures at the station are presented, the measurements are described, results are presented and conclusions and summary were also given.

The Sun's distance from Earth is about 400 times the Moon's distance, and the Sun's diameter is about 400 times the Moon's diameter. Because these ratios are approximately the same, the Sun and the Moon as seen from Earth appear to be approximately the same size: about 0.5 degree of arc in angular measure. A separate category of solar eclipses is that of the Sun being occluded by a body other than the Earth's moon, as can be observed at points in space away from the Earth's surface. Two examples are when the crew of Apollo 12 observed the Earth eclipse the Sun in 1969 and when the Cassini probe observed Saturn eclipsing the Sun in 2006 [3].

\section{The Study AREAS (Nigeria ANd Katsina StATE)}

Nigeria is located in western Africa on the Gulf of Guinea and has a total area of $923,768 \mathrm{~km}^{2}(356,669 \mathrm{sq} \mathrm{mi})$ It is situated in the West African region and lies between longitudes 3 degrees and 14 degrees and latitudes 4 degrees and 14 degrees (see figure 1). It has a land mass of 923,768 sq.km. It shares a 4,047-kilometre $(2,515 \mathrm{mi})$ border with Benin $(773 \mathrm{~km})$, Niger $(1497 \mathrm{~km})$, Chad $(87 \mathrm{~km})$, and Cameroon $(1690 \mathrm{~km})$, and has a coastline of at least $853 \mathrm{~km}$. Nigeria lies between latitudes $4^{\circ}$ and $14^{\circ} \mathrm{N}$, and longitudes $2^{\circ}$ and $15^{\circ} \mathrm{E}$. The highest point in Nigeria is Chappal Waddi at $2,419 \mathrm{~m}(7,936 \mathrm{ft})$. The main rivers are the Niger and the Benue, which converge and empty into the Niger Delta. This is one of the world's largest river deltas, and the location of a large area of Central African mangroves [9].

Nigeria has a varied landscape. The far south is defined by its tropical rainforest climate, where annual rainfall is 60 to 80 inches $(1,500$ to $2,000 \mathrm{~mm})$ a year. In the southeast stands the Obudu Plateau. Coastal plains are found in both the southwest and the southeast. This forest zone's most southerly portion is defined as salt water swamp, also known as a mangrove swamp because of the large amount of mangroves in the area. North of this is fresh water swamp, containing different vegetation from the salt water swamp, and north of that is rainforest. It is found in the Tropics, where the climate is seasonally damp and very humid. Nigeria is affected by four climate types; these climate types are distinguishable, as one moves from the southern part of Nigeria to the northern part of Nigeria through the middle belt.

\section{A. Climate and Vegetation}

Temperatures across the country are relatively high with a very narrow variation in seasonal and diurnal ranges (22-36t). There are two basic seasons; wet season which lasts from April to October; and the dry season which lasts from November till March. The dry season commences with Harmattan, a dry chilly spell that lasts till February and is associated with lower temperatures, a dusty and hazy atmosphere brought about by the North-Easterly winds blowing from the Arabian peninsula across the Sahara; the second half of the dry season, FebruaryMarch, is the hottest period of the year when temperatures range from 33 to 38 degrees centigrade.

Half of the dry season, February-March, is the hottest period of the year when temperatures range from 33 to 38 degrees centigrade. The extremes of the wet season are felt on the southeastern coast where annual rainfall might reach up to $330 \mathrm{~cm}$; while the extremes of the dry season, in aridity and high temperatures are felt in the extreme northern part of the country.

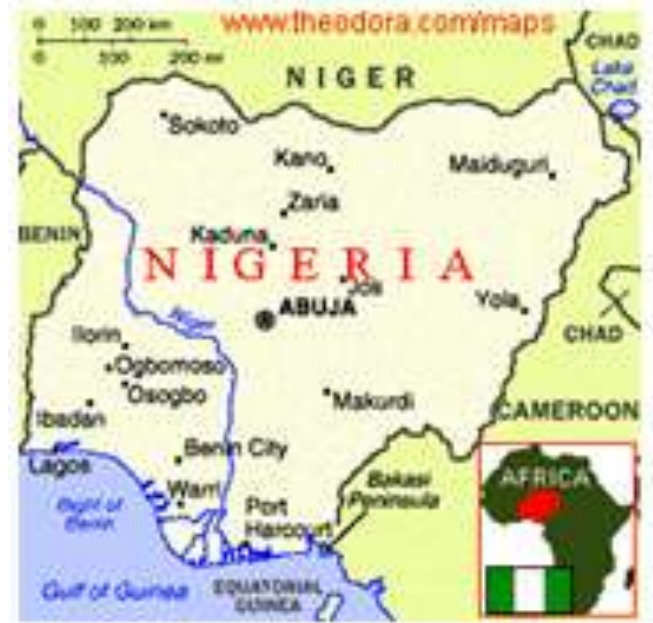

Fig. 1: Map of Nigeria showing the States. Source: Geological Survey, 2009

In line with rainfall distribution, a wetter south and a drier northern half, there are two broad vegetation types: Forests and Savanna. There are three variants of each, running as near parallel bands east to west across the country. Forests Savanna Saline water swamp Guinea Savanna Fresh water swamp Sudan Savanna Tropical (high) evergreen Sahel Savanna Rainforest. There is also the mountain vegetation of the isolated high plateau regions on the far eastern extremes of the country (Jos, Mambilla, Obudu). The savanna, especially Guinea and Sudan, are the major grains, grasses, tubers, vegetable and cotton growing regions. The Tropical evergreen rain forest belt bears timber production and forest development, production of cassava; and plantation growing of fruit trees-citrus, oil palm, cocoa and rubber, among others.

Katsina metropolis (city) is situated between Latitudes $11^{\circ}$ $18^{\prime} \mathrm{N}$ and $13^{\circ} 22^{\prime} \mathrm{N}$, and Longitudes $6^{\circ} 52^{\prime} \mathrm{E}$ and $9^{\circ} 20^{\prime} \mathrm{E}$. It was built on a spur of land between Ginzo and Tilla streams which flows in a north-easterly direction, and is at a narrow neck of water shed between the Gada and Tagwai River Basin (Figure 2.1). Katsina is an ancient old City that was formerly a City State surrounded by City wall of 21 kilometers in 
diameter/length Katsina is a local government Headquarter and the capital city of Katsina State. It is one of the 36 States that comprises the Federal Republic of Nigeria. The city is moderately populated with about 700,000 persons/settlers been recent estimates mainly as a result of natural increase and migration from other cities that were affected by insecurity in northern Nigeria. The climate is Tropical Continental type, classified according to Kopen's Climate Classification as AW, with long dry season and short wet season [10].

Vegetation type is Sudan Savannah with short scattered trees and grasses. Most of the vegetation is affected by human activities such as deforestation for fuel wood and clearance of vegetation for residential purpose [10].

The geology of the area governs the nature of river flowage. The project area lies within the Nigerian Basement Complex which is divided into Crystalline basement of migmatites and gneisses. The crystalline basement initially behaved as one tectonic unit, but later experienced two periods of syntectonic metamorphisms with deformations in two successive phases called the Intense Alpine types deformations. The deformations took place during the Pan African Orogeny which were accompanied by metamorphism, granitization and feldspatization. The first tectonics resulted in extensive migmatisation of the basement but was further differentiated during the second tectonics to produce homogenous gneiss and intrusive granites [9]

The migmatites and gneiss represent the oldest rocks in the basement complex [9] There are at least two generations of migmatitic gneiss of widely different ages within the study area. The migmatitic gneiss underlie mica schist, dipping south-east at between 270 and 430 with most outcrops observed in stream channels. The mica schists are generally fissile dark-grey to greenish grey in color and weather to a silvery to a light grey colored with red iron- oxide stains on its fissile surfaces.

\section{EXPERIMENTAL PROCEDURES}

Due to the proximity to the total eclipse site at Igboho, the University of Ilorin and the university of Ibadan base been selected by the Nigerian National IHY Coordinator as closeby take-off sites far scientists viewing the total Solar Eclipse. The Ilorin site has an advantage of being a Baseline Surface Radiation Network (BSRN) candidate site with several operational instruments for environmental monitoring (Pinker et al., 2001; Pandithurai et al., 2001; Holben et al., 2001; Smirnov et al., 2003; Pinker et al., 2005) [3]. These include Pyranometers, Pirgeometers, Pressure and temperature sensors and AERONET Cimel sensors. During the Eclipse, a Photodiode (BWP 21) mounted to the base of a collimator of $5 \mathrm{~cm}$ length by $1 \mathrm{~cm}$ diameter and coated black inside was used to record direct radiation (in arbitrary units). The BWP 21 Photodiode was housed in a hermetically sealed can with a flat window incorporating correction filter for visible radiation. It has peak spectral response of $560 \mathrm{~nm}$ and operates in the wavelength range of $46 \mathrm{~nm}$ to $750 \mathrm{~nm}$. It has a short circuit sensitivity of $7 \mathrm{nA} / \mathrm{lux}$ and is made of RS components Ltd., Birchington Road, Corby, Northants, NN 17 9R5, UK. The time was measured using an LCD digital clock and correlated with GPS Direct solar radiation flux measurement could be made with this arrangement as the moon traversed the sun disc. The data were taken at 1 minute intervals. At the Ilorin location, PSP Eppley radiometers are operating in the wavelength in the range of $200 \mathrm{~nm}$ to $2800 \mathrm{~nm}$ to measure diffuse and global radiation and other sensors measure air temperature and Relative Humidity while a Cimel sunphototometer measures spectral AOD at selected wavelengths and contributes the data to the ARTONET network.

\section{MEASUREMENTS}

\subsection{Direct solar radiation}

During the Eclipse, the size of the bright part of the Sun diminished until the Moon's disc completely covered that of sun (as observed with the protective glasses) between 09:23 and 09:27 GMT. Subsequently, the bright portion of the sun Eclipse changed from one side to the other. The full brightness of the sun was observed again at 09:49 GMT [4]. The corresponding photo-sensor reading decreased from before 09:00 GMT until about 09:23 GMT and 09:27 GMT, it started to increase again. The sequence of measurements of the direct solar radiation flux presented is in Figure 2.

Temperature: The temperature was measured on a flat rooftop at a site synonymous with Adeniyi, et al. (2006). It showed a drop in value between 09:08 and 09:58 GMT with a minimum at about 9.32 GMT (Figure 1). The decrease in temperature as not us rapid as the direct solar radiation flux but as gradual with a minimum occurring between 09:4 and 09:38 GMT. The number of data points considered per hour in this measurement is much larger than reported by Szalowski [5].

Relative Humidity: Relative Humidity (RH) measurements showed an increase during the Eclipse period (figure 1) to a maximum before decreasing. The peak value of the $\mathrm{RH}$ is more pronounced than that of the temperature It occurred about the same time as the minimum in solar radiation and the change is nearly symmetrical about the peak position.

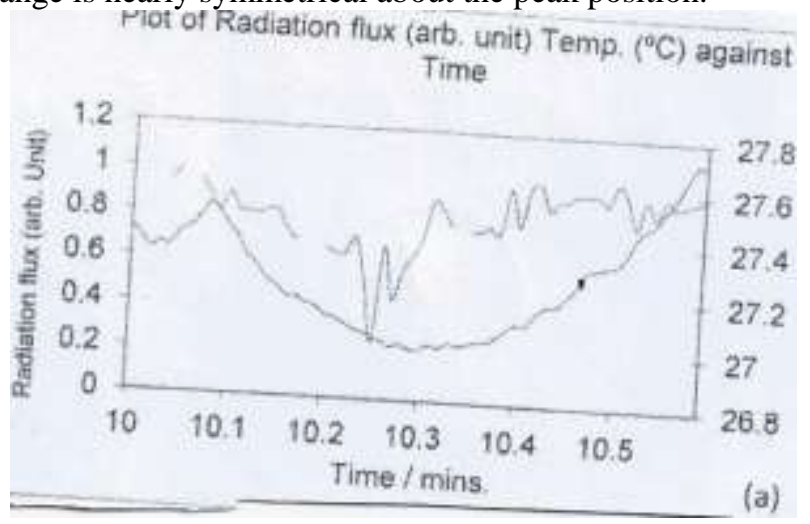




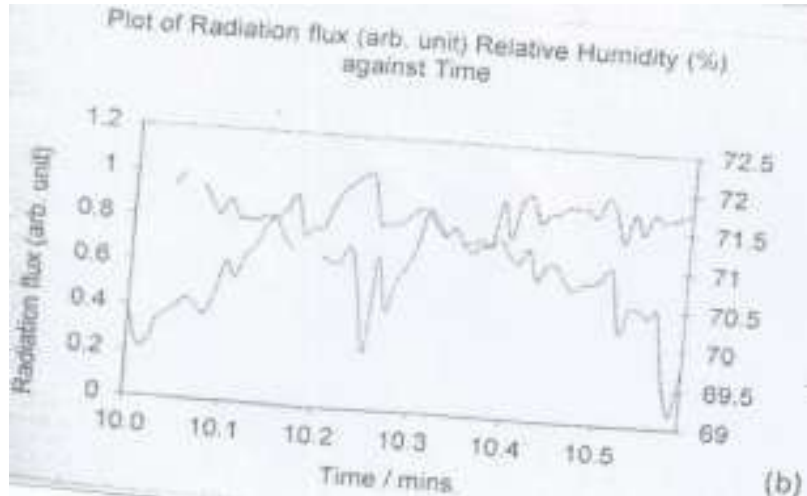

Fig. 2: Plot of (a) Solar Radiaton flux (arbitrary units) and Temperature $\left({ }^{\circ} \mathrm{C}\right.$ ) against local time and (b) Solar Radiation flux (arbitrary units) and Relative Humidity (\%) against local time.

Aerosol Optical Depth: The Aerosol Optical Depth (AOD) was observed at $500 \mathrm{~nm}$ with the Cimel sun-photometer during the Eclipse period at the Ilorin site. The AOD showed a change in value from 0.6 to 2.5 as shown in Figure 2. Even though the aerosol measurements are less frequent than the others, taken at initials of about 30 minutes, the peak AOD value occurred within 60 minutes changing from 1.25 to 2.5 . The AOD change was solely due to the diminishing incident solar radiation during the Eclipse rather than due to increase in aerosols or clouds. It is conspicuously different from AOD plots of day 87 and 89 .

\section{Analysis}

Direct Solar Radiation Measurement: Direct Solar Radiation flux fell to about one third its value in less than 20 minutes and rose again to the same starting level at about the same time interval as shown in Figure 2. The sharpest decrease however occurred within \pm 5 minutes of the minimum about GMT 9:25. Air Temperature: Comparison of air temperature profile with the corresponding plot for the previous day 87 and the day after, 89 is shown in Figure 3 The plot showed a drop of $0.4^{\circ} \mathrm{C}$ to a minimum of $27.1^{\circ} \mathrm{c}$ from an earlier peak value of $27.5^{\circ} \mathrm{C}$ in about 20 minutes as a result of the Eclipse. The temperature change was ma as rapid as the solar radiation change.

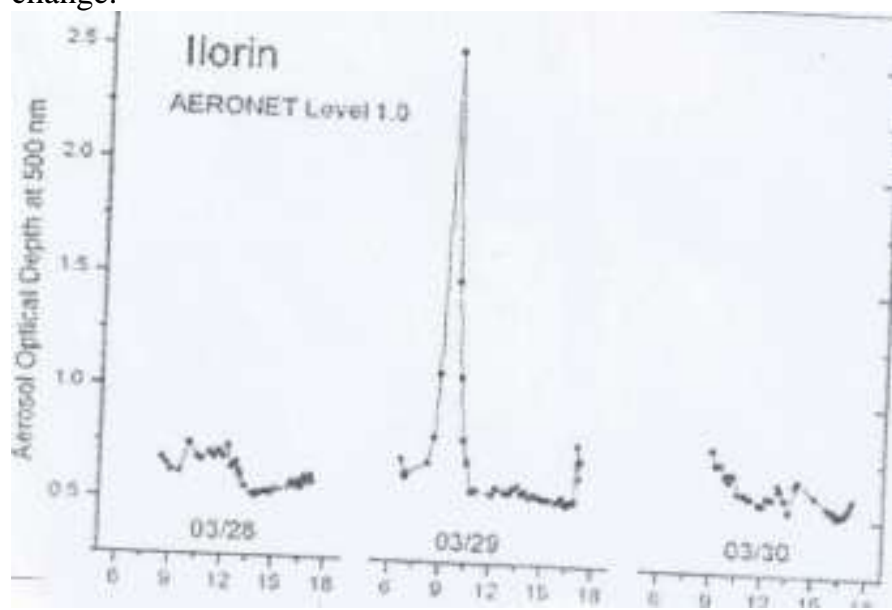

Fig. 3. Aerosol Optical Depth plotted against time showing comparison of value obtained on Julian days 87,88 (Eclipse day) and 89 .

Figure 3. Temperature-time profile compared for Julian days 87 (highest), 88 (lowest) and 89 (middle). The Eclipse occurred on Julian Day 88.

Relative Humidity: The Relative Humidity Value increased from $69.6 \%$ to a maximum of $72 \%$ in about 20 minutes during the Solar Eclipse. It also showed a quadratic dependence on time [6].

Aerosol Optical Depth: The AOD increased due to reduced solar radiation during the Eclipse as shown in Figure 2. Measurement made with the Cimel showed an increase in aerosol optical depth increased from about 0.7 to a maximum of about 2.5 at $500 \mathrm{~nm}$ wavelengths. The drop in intensity at this wavelength without a corresponding decrease in aerosol content showed as the observed increment.

There is a significant reduction in direct solar radiation as the moon traverses the sun disc and the visible wavelength is significantly cut off. However, it did not come to absolute zero but to a low minimum and only radiation from the edges of the Umbra reaches the Earth.

\section{SUMMARY}

The results presented above showed that the occurrence of the eclipse produced changes in several measured optical and meteorological parameters. During the eclipse, the solar radiation and temperature dropped to a minimum before rising again while the relative humidity increased to a maximum before dropping again. The changes in relative humidity due to the reduction of incident solar radiation seem precede that of temperature. The relationship between the temperature change and relative humidity seem to be inverse to each other. The plot of RH against Temperature shown in Figure 4. gives a negative slope linear dependence with correlation factor 0.85 [7].

$$
\begin{aligned}
& \text { RH }=-b_{11} T+b_{12} \\
& \text { Where } b_{11}=2.7 .
\end{aligned}
$$

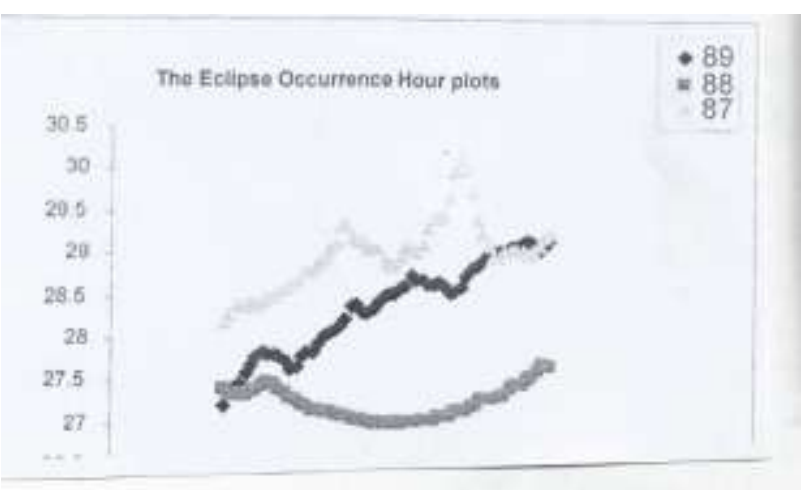




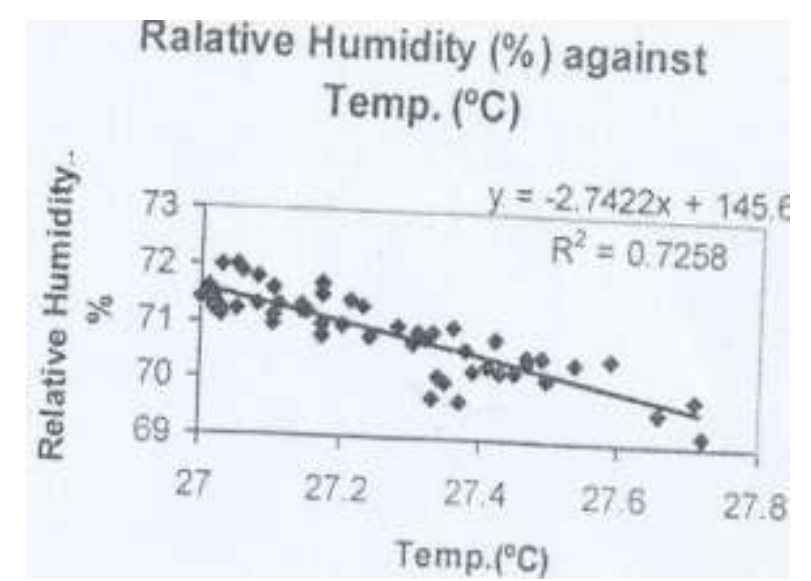

Fig. 4 and 5: Plot of observed Relative Humidity against temperature during Eclipse period.

There is no noticeable or significant change in pressure during the eclipse. The solar eclipse can be considered as an experiment organized by nature. In addition to the above, biological effects were observed. For example, the biological clock of chickens was found to be affected causing them to go their cages and as soon as the sun came back, they returned to the open space.

\subsection{Impact of the Eclipse}

Blackouts, hyperactive squirrels and gravity breaking are just some of the things that happen during the eclipse. It means the moon has passed in front of the sun and blocked it out. At worst, it will be a bit cold and dark for a few minutes. But there are some unexpected consequences of the eclipse that the residents were not aware of [8].

Running Out of Electricity: The European Union generates approximately $95 \mathrm{GW}$ of solar power, a significant proportion of its energy production. The extra darkness caused by the upcoming eclipse could cause this to drop by up to $35 \mathrm{GW}$. That's three times the power output of all the nuclear power plants in the UK combined. Wind power is predicted to drop too, as eclipses can cause wind speeds to drop by nearly $1 \mathrm{~m} / \mathrm{s}$. Best not have that cup of tea while you're waiting for the sun to stop hiding.

Components of Ecosystem Acted strangely: Animals rely on a day/night cycle in order to function correctly, and the sudden darkness can trick animals into switching their behaviour to night time mode. Nocturnal animals such as crickets start chirping, mosquitoes come out to feed, and predators such as owls wake up and venture out of the nest. Other birds, such as geese, instinctively return to roost when the eclipse starts, only to pull a U-turn when it ends. Cicadas, normally very loud creatures, stop singing to conserve energy. Other animals just freaked out. Bees markedly increase activity, possibly out of fear that plants may die. Squirrels too fear for food, and run around far more than usual. But, feel sorry for hippos. They get scared and hide underwater until it stops.

Fear of Death (if you don't notice the sun has gone): Eclipses were historically considered ill omens by many cultures, but few considered them as portentous as the ancient Chinese. Approximately 4,000 years ago, two astronomers called Hsi and Ho were tasked with predicting solar eclipses in an effort to stay ahead of ill fortune, however their solitude soon begat drunkenness, and they not only failed to predict an eclipse, but also failed to notice it entirely. For this failure, they were executed.

Gravity Stops Working: Despite all of the strange myths surrounding eclipses, you could probably forgiven for thinking that at least you could stay standing up without difficulty. Except, there is a well documented and completely unexplainable phenomenon that gravity simply doesn't work properly during total eclipses, but only for pendula. It's called the Allais Effect, after Marcus Allais, the Nobel Prize winning economist, who first observed this effect in the 1950s. Since then, scientists have reported everything from pendula starting to swing faster, to changing amplitude and being knocked as if hit by a shockwave. Many have also failed to notice any effect at all. Nevertheless, the only explanation offered so far is that there must be gravitational waves blocked by the moon, which does not conform to any theory of gravity yet discovered [2].

Prayers Needed: The Islamic ritualistic prayer should take place five times a day. However, in the event of a solar eclipse, this increases to six prayers, the extra being the Salat al-Ayat, or Prayer of the Signs. This is offered out of respect for Allah's command over nature, and is not just limited to solar eclipses. Any "Sign of God", such as lunar eclipses or even earthquakes require this prayer.

You could go hungry: Eclipses can be bad omens indeed, especially if you live in India, and have just sat down to tea. The belief is that the sun's rays help keep disease away, and that during a solar eclipse the lack of these rays causes food to be poisoned. Food is not prepared during an eclipse, nor eaten, and any prepared food is thrown away. However, since the UV light from the sun does have a small antibiotic effect, perhaps this one isn't too farfetched after all [2,8,].

Spiritual significance of a Solar or Lunar eclipse: Spiritual research has shown that in the case of all eclipses there is a rise in the Raja-Tama and a reduction in the Sattva component. This rise in Raja-Tama has many detrimental sideeffects at a subtle (intangible) level which may not be noticeable in the physical plane initially. However these RajaTama laden conditions are made use of by ghosts to harm society. Due to the Sun being obscured by a subtle barrier in front of the gross or subtle Sun during an eclipse, there are two significant spiritual impacts:

The environment becomes conducive for negative energies to amass black energy. Black energy is a type of spiritual energy that is the primary weapon of attack of ghosts.

The environment is most conducive for negative energies to utilize their black energy to harm humankind during the period of the eclipse as well as to sow the seeds of destruction of humankind.

In the case of physical eclipses, the reason for increased Raja-Tama is due to the fact that during an eclipse the light from the Sun or the Moon is obstructed even before it reaches the Earth. This darkness is an anomaly in the general cycle of day and night wherein a period that should have been in light is now in darkness. In fact, the spiritually detrimental effect of the phenomenon of night is equivalent to just $2 \%$ as that of an 
eclipse. This is insofar as the negative energies' ability to use the darkness and its resulting increase in Raja-Tama to harm society.

In the case of a subtle eclipse, a higher order of ghosts creates a black negative energy barrier between the Sun and the Earth and also directly attacks the subtle Sun. This obstruction again causes an increase in Raja-Tama [1,3,5].

Impact of Solar and Lunar eclipses at an individual level: At the time of an eclipse, people are more likely to be affected by their departed ancestors. In many cases, departed ancestors create problems in their descendants' lives. To do this departed ancestors take advantage of the excess Raja-Tama and the heightened black energy created by ghosts at the time of an eclipse.

It is for this reason people may experience lethargy, tiredness, sickness etc. at a physical level. At the psychological level, there are excess emotional and negative thoughts, especially about spiritual practice. The moon is known to affect the mind. During a full moon, the effect is even more pronounced. This is further accentuated when there is a lunar eclipse. Thus the combination of the full moon and lunar eclipse is severe. However it happens at a subtle intangible level, i.e. people suffer distress by negative energies.

There is a general decline in decision-making capacity and people are more likely to make incorrect decisions as the intellect is also affected.

Impact of eclipses at the level of humankind: As mentioned earlier, ghosts use the excess Raja-Tama generated from an eclipse to collect black energy. They use this black energy to harm humankind in various ways. They do this by sowing seeds of destruction and harm at a subtle intangible level that only manifest in the physical plane after a gestation period. This gestation period can be anywhere from a few days to several years. Examples of this would be sowing seeds of pandemics of contagious diseases like Bird Flu and the Ebola Virus or sowing seeds of the third World War. Eclipses contribute in a large way by providing circumstances conducive to amassing the black energy that ghosts have. In our article on World War 3 Predictions and Armageddon we mentioned that the world will go through a World War and major natural disasters between the years 2015 and 2023. It will be accompanied by an unprecedented loss of human life. The main catalyst at a subtle intangible level for World War III will be higher-level ghosts. They will orchestrate these events through their black energy influencing man to wage war against his fellowmen. Up to $30 \%$ of all their black energy will be gathered at the time of eclipses. The following table shows a breakdown of the factors that will help make the environment conducive for ghosts to create their black energy $[6,8]$.

Effect on Wind Action and Movement: Solar eclipses don't just turn the lights out - they also make the wind slow down and change direction.

Solar eclipses don't just turn the lights out, they also make the wind slow down and change direction. Scientists compared hourly measurements of wind speed and direction from 121 weather stations across southern England during the August 1999 total solar eclipse with the output of a high-resolution weather forecast model that wasn't programmed to represent the eclipse.

The model agreed very closely with the instruments' readings right up until the eclipse began. It then showed what the weather would have been like if the eclipse hadn't happened, giving researchers a much more accurate idea of its effects. The eclipse was like a giant natural experiment. The study shows that scientists can now use high-resolution weather models to look at local weather changes of small magnitude, like those caused by solar eclipses. The results show that average wind speed across an inland cloud-free region over southern England dropped by 0.7 metres per second, and that the wind's direction turned anticlockwise by an average of $17^{\circ}$ - effectively, the eclipse was causing the winds to become more easterly. Temperatures also fell by an average of about $1^{\circ} \mathrm{C}$.

Previous work on the subject has been based only on measurements in a few places, rather than from a network as in this case. And it didn't compare these measurements with a weather model to predict what would have happened without the eclipse. It's only recently become possible to do this kind of experiment, after huge improvement in high-resolution weather forecast models over the last decade.

We could never have done this when the eclipse occurred. But now we can use the model to get a far better idea of its impact on the wind. Temperatures are likely to fall when the Earth is deprived of sunlight, just like they do at night. And the slower wind speeds weren't unexpected, Gray says - cooling the atmosphere close to the ground removes energy from it, damping turbulence, which will probably mean less wind. But the changes in wind direction were more of a surprise.

The effects were so pronounced that they can be seen even in measurements that are taken hourly, which is very infrequent in the context of such a transient event as an eclipse. The results seem to fit the 'eclipse cyclone' hypothesis proposed in 1901 by $\mathrm{H}$. Helm Clayton, one of the first scientists to investigate eclipses' impact on the weather. He suggested that when the moon's gigantic shadow falls on the Earth, it causes a core of cold air around which a weak, shortlived cyclone forms, skewing the winds anticlockwise. According to a new paper in Proceedings of the Royal Society A., solar eclipses make the wind slow down and change direction.

\section{REFERENCES}

[1] Gruschin, G.P and N.N. Vinogrradov, (1983). Total Ozone in the Atmosphere, Leningrad, Gidrometeoizdat, 238 (1983).

[2] Espenak. F. and J Anderson, 2006. NASA Eclipse Bulletin.

[3] Adeniyi, J. O. Radicella, S. M.., Adimula, I. A., Willoughby, A. A., Oladipo O.A. and Olawepo O., (2006). Signature of the 29 March 2006 eclipse on the ionosphere over an equatorial station, Jour. Geophysical Research, 112, A06314, doi: 10.1029/2006 JAO, 12197,2007.

[4] Skinner. N. J. (2007), Eclipse effects in the equatorial F-region, J. atmos. and Terr, Phys., 29,287 - 295, https://doi.org/10.1016/0021-9169(67)90198-5

[5] N. J. Skinner, (1969) A new analysis of eclipse effects in the equatorial F-region, J atmos.Terr. Phys.31 ppl333 to 1333.

[6] Karol Szalowski, (2002). The effect of the solar eclipse on the air temperature near the ground, J.atmos. and Solar-Terr, Phys., 64, pp1589 to 1600 . https://doi.org/10.1016/s1364-6826(02)00134-7 
[7] Pinker, R. T., G. Pandithurai, B. N. Holben, O. Dubovik, and T. O. Aro, (2001). A dust outbreak episode in sub-sahel West Africa. J. Geophys. Res., 106, No. D19, 22,923-22,930. https://doi.org/10.1029/2001jd900118

[8] Pandithurai, G., R. T. Pinker, O. Dubovik, B.N. Hoben, and T.O. Aro, (2001) Remote Sensing of Dust Optical Characteristics in Sub-Sahel, West Africa. J. Geophys. Res., 106, no. D22, 28,347- 28,356. https://doi.org/10.1029/2001JD900234

[9] Kankara, I. A. (2008). Environmental Sustainability In Africa: An Assessment of Sustainable Access to Safe Drinking Water in the Continent. A paper presented at National Conference of Social Sciences, held at University of Maiduguri, 28/11/2008.

[10] Ladan, I. (2014) Environmental Sciences, a lecture series for 400 Level Students, Al-Qalam University Katsina. 